\title{
EDITORIAL
}

\section{The new curriculum for psychiatric training}

\section{Dinesh Bhugra}

\begin{abstract}
The UK's Postgraduate Medical Education and Training Board (PMETB) went live on 30 September 2005. This editorial summarises the state of play and informs members of the Royal College of Psychiatrists and stakeholders of the changes that have taken place in the intervening year and of the College's response. The College has received provisional approval of its core curriculum, and specialty curricula have been submitted for approval. We are in the middle of pilot work on workplace-based assessments and preliminary results should be available in the early part of 2007, when trainees and educational supervisors will begin training in the preparation for and carrying out of these assessments.
\end{abstract}

Training in any subject and any field follows a trail of knowledge and skills, which are built upon by experience. Training allows professionals to be clear about what their professional qualifications mean, and the nature of their professionalism is embedded in the knowledge, skills and experience that they acquire. Training in medical specialties needs these three key elements, no matter where in the world it occurs. In recent years, undergraduate medical training in the UK underwent a significant change in providing problem-based learning. Time has dictated that, in view of the changing expectations of patients, carers and policy makers, the medical profession looks at postgraduate training as well.

One of the key responsibilities of the newly formed Postgraduate Medical Education and Training Board (PMETB) has been to get the medical Royal Colleges to develop curricula in their respective specialties. To this end the Royal College of Psychiatrists was the second College to have its core curriculum provisionally approved, earlier this year (Box 1). Entitled A Competency Based Curriculum for Specialist Training in Psychiatry (Royal College of Psychiatrists, $2006 a$ ), it took over 18 months to develop, and a small group of committed and dedicated individuals, including potential stakeholders in the curriculum - trainees and medical students - went beyond the call of duty to achieve this.

\section{Design}

The College's curriculum has been designed not just to meet but to go beyond the standards and requirements set out by the PMETB (2004a, $2005 a)$. As the UK statutory authority for quality and standards in postgraduate medical education, PMETB is required to approve all aspects of the curriculum and its delivery, as well as assessments that determine whether the curriculum is being followed and that the assessments themselves are fit for purpose.

In ensuring that our curriculum is, indeed, of a high standard, a number of innovative features have

Box 1 The primary focus of the 6 years of specialist training in psychiatry (ST1-ST6)

- ST1-ST3 focus predominantly on general psychiatric competencies, including developmental psychiatry

- ST4 and ST5 concentrate on specialty competencies

- ST6 focuses on preparing to become a consultant 
been incorporated which are now being followed by other medical Royal Colleges. The curriculum is in an electronic format rather than the traditional printed booklet, which makes it more accessible and easy to use both for trainees and trainers (Royal College of Psychiatrists, 2006a). It also makes it relatively easy to update. Another advantage is that publication on the College's website puts the curriculum in the public domain.

\section{Principles}

The curriculum is based on important principles of medical education. It is patient-based and learnercentred, which allows trainees to be in control of their training needs through regular discussions with their educational supervisors. It is designed to promote excellent patient care and relevant, contextual learning for trainees that is a mixture of knowledge, experience and skills. Rather than simply listing topics to be learned, as traditional medical curricula and syllabuses did, the College's new curriculum defines competencies that psychiatrists have to acquire and demonstrate in their day-to-day clinical practice. These competencies were developed following the domains of Good Medical Practice (General Medical Council, 2001) but were also influenced by our own Good Psychiatric Practice (Royal College of Psychiatrists, 2004). The competencies are rated at different levels, depending on the year of training, thereby illustrating not simply the period of training but more specifically the progress of professional development. These levels of competency rate performance from 'under supervision' to 'competent', and beyond to 'mastery', again reflecting the high standards that the College is keen to promote.

Not only does our curriculum differ significantly from previous versions in its content and presentation, it also incorporates an assessment programme, as PMETB standards require. The board proposes an overarching assessment strategy consisting of workplace-based assessments and examinations of knowledge and clinical skills (Postgraduate Medical Education and Training Board, 2004b, 2005b). This assessment strategy must relate to the entire training period, rather than only discrete points (such as scheduled examinations) along the way, as was the case previously. Clearly, the focus of postgraduate training is moving rapidly away from just gaining a certain number of marks in high-stakes examinations, which sometimes pass people who are good at passing examinations and fail others who are in every other way perfectly competent psychiatrists.

\section{Assessment}

This move towards gathering evidence of clinical competence and appropriate professional behaviour and attitudes ensures that the skills needed to practise safely and competently are tested, in addition to the core knowledge of the subject. Much of this evidence cannot be captured in the kind of formal examinations that have traditionally been the primary focus in postgraduate training. The clinical competencies will be assessed when the trainee is in the workplace and is able to demonstrate them, day in and day out. As competencies and learning are both demonstrated and observed in the workplace, it stands to reason that the workplace is where the evidence for their attainment must be gathered. Workplace-based assessments will therefore become increasingly important over the next few years, which is why, along with workplace-based learning, they are such an important feature of the College's curriculum. These assessments may be carried out by various stakeholders, including clinicians, educational supervisors and professionals trained in assessment methods. They will include patientand carer-satisfaction questionnaires, which can be particularly problematic for some of our patient groups. However, this is being explored further in pilot studies.

On 1 August 2006, 15 pilot sites across the UK started using at least one of the College's workplacebased assessments (three deaneries are using all of them, to determine the level of resources that will be required to deliver such assessments). Preliminary results from these sites are expected towards the end of this year and these will determine which assessments the College chooses and accordingly introduces in the training programmes for assessors and trainees from January 2007.

As noted above, the core curriculum is set out under the domains of the General Medical Council's Good Medical Practice and the content is organised in a hierarchical structure within each domain. This structure descends through the sub-headings that Good Medical Practice uses for each domain, then through the major competencies for each subheading. Most of the major competencies have a number of aspects, and the supporting competencies for each aspect are set out under the headings of knowledge, skills and attitudes. Hyperlinks are embedded to facilitate navigation (in both directions) through the curriculum.

Developing performance is indicated for major competencies or aspects of competencies under the headings of 'under supervision' 'competent' and 'mastery'. The stage of training at which 'under supervision' and 'competent' levels of performance 


\begin{tabular}{|c|c|c|}
\hline Part & Year & Means of assessment and primary focus of curriculum \\
\hline I & ST1 & $\begin{array}{l}\text { Formal assessment of application of knowledge using examination papers presenting } \\
\text { multiple choice questions (MCQs) and extended matching questions (EMQs) }\end{array}$ \\
\hline II & ST2 and ST3 & $\begin{array}{l}\text { Formal assessment of clinical performance using possibly } 20 \text { objective structured clinical } \\
\text { examination (OSCE) stations } \\
\text { Test of knowledge (format yet to be determined) of specialties that have not previously been } \\
\text { tested in ST1, e.g. child psychiatry and learning disability }\end{array}$ \\
\hline III & ST4 and ST5 & $\begin{array}{l}\text { Global assessment of performance, including a review of workplace-based assessments, in } \\
\text { the psychiatric specialty chosen by the trainee }\end{array}$ \\
\hline
\end{tabular}

are expected is indicated by the use of coloured text: red indicates specialist training stage 1 (ST1); orange ST2 and ST3; violet ST4 and ST5; and green ST6.

\section{Progress}

Progress through the core curriculum will depend on successfully demonstrating at a number of assessments that the expected level of competencies has been reached. The College Membership examinations (the MRCPsych, Parts I and II) will remain and form an integral part of the overall assessments. However, a Part III examination will be added, which will focus on the psychiatric specialty chosen by the trainee. It is likely that the new Part I and Part II examinations will be in place by the spring of 2008, and Part III will be introduced in 2012/2013. Table 1 shows how the MRCPsych examinations map onto the primary focus and key assessment methods for each year of training.

The core curriculum also contains supporting materials, which are listed in an Appendix (Royal College of Psychiatrists (2006b). The preparations for implementation are already underway. The specialty-specific curricula have been submitted to PMETB.

The full curriculum assumes a 6-year training period but it has inbuilt flexibility, so that those who reach levels of competencies earlier can be signed off if and when they feel ready to complete their assessments. The first 3 years of specialist training (ST1-ST3), called core training, focus predominantly on general psychiatric competencies and include developmental psychiatry, whereas the next 2 years (ST4 and ST5) concentrate on specialty competencies. The final year (ST6) will be used for preparation to become a consultant. The research and special interest sessions will change so that, in the final 3 years of their training, trainees can spend time on service development and/or research, or develop special interest sessions in clinical matters. Like the curricula, trainees' portfolios of progress and attainment will also be electronic. The College is currently investigating which electronic systems can be used for the collation of these data. The mapping of the syllabic content onto the curriculum is well underway, and appendices that include suggested learning and assessment methods and other sources of evidence are being developed.

\section{The future}

Online support materials for the curriculum are being prepared and should be available in time for the introduction of the unified training grade in August 2007. A new set of committees is being set up in each Faculty to advise on curricular content and assessment standards and tools. In addition, curriculum, assessment and quality assurance committees are being set up to take the task forward. All these committees will have lay input and their minutes will be in the public domain, to meet the PMETB expectations. The College is ready not only to meet their expectations but in many areas to exceed them. These are very exciting times and it is vital that the profession meets the needs of our patients and their carers, who deserve the best treatment they can get.

\section{Declaration of interest}

D.B. is Dean of the Royal College of Psychiatrists.

\section{References}

General Medical Council (2001) Good Medical Practice (3rd edn). London: GMC.

Postgraduate Medical Education and Training Board (2004a) Standards for Curricula. London: PMETB.

Postgraduate Medical Education and Training Board (2004b) Principles for an Assessment System for Postgraduate Medical Training. London: PMETB.

Postgraduate Medical Education and Training Board (2005a) What is Curriculum? http://www.pmetb.org.uk/media/pdf/ e/f/What_is_Curriculum_1.pdf 


\section{Bhugra}

Postgraduate Medical Education and Training Board (2005b) Workplace Based Assessment. A Paper from the PMETB Workplace Based Assessment Subcommittee: January 2005. London: PMETB.

Royal College of Psychiatrists (2004) Good Psychiatric Practice (2nd edn) (Council Report CR125). London: Royal College of Psychiatrists.

Royal College of Psychiatrists (2006a) A Competency Based Curriculum for Specialist Training in Psychiatry: Core and General
Module. London: Royal College of Psychiatrists. http:/ /www. rcpsych.ac.uk/PDF/Curriculum $\% 20-\% 20$ core $\% 20$ and $\% 20$ ge neral\%20module.pdf

Royal College of Psychiatrists (2006b) Appendix 1: Syllabic curriculum content: Summary of Areas of Core Medical Knowledge Underpinning Specialist Training in Psychiatry. London: Royal College of Psychiatrists. http://www.rcpsych.ac.uk/pdf/ Appendix\%201\%20-\%20Syllabic\%20content.pdf 